\title{
Sous la direction de J.L. Drape, A. Blum, C. Cyteval, T. Pham, G. Dautel, N. Boutry, D. Godefroy: Poignet et main (Wrist and hand)
}

\author{
GETROA-GEL, Opus XXXVI, Sauramps Médical, 2009, 133,00 €, \\ ISBN: 978-2-84023-618-4
}

\section{Alain Graftiaux}

Received: 20 December 2010/Accepted: 21 December 2010/Published online: 19 January 2011

(c) Springer-Verlag 2011

This book takes again the subjects of days SIMS of June 2001 and milked: the imagery and the pathology of the wrist and the hand. Progress of these last years makes it possible to see much more things in echography, CT and MRI. This book gives a description of the novel methods by bringing closer the private clinic, the anatomy and the new indications in imagery. Several great chapters treat synovial tendinopathies and cysts, canal syndromes, rheumatologic hand, vascular pathologies, traumatic wrist and pathologies of the fingers.

This book makes it possible for a surgeon to give a progress report on the possibilities of diagnosis with imagery on rare pathologies like the syndrome of the crossing for example, or to have an idea of the contribution of new examinations like echography in the carpel tunnel for example, or the respective interest of the scanner and the MRI in pathologies of the wrist.

A little part of imagery does not harm and makes it possible to better target the examinations for a better diagnosis.

Conflict of interest No funds were received in support of this study. 